\title{
Why Immersive, Interactive Simulation Belongs in the Pedagogical Toolkit of "Next Generation" Science
}

\section{Citation}

Tutwiler, M. Shane, and Tina Grotzer. 2013. Why Immersive, Interactive Simulation Belongs in the Pedagogical Toolkit of "Next Generation" Science: Facilitating Student Understanding of Complex Causal Dynamics. In Approaches and Strategies in Next Generation Science Learning, eds. Myint Swe Khine and Issa M. Saleh, 127-146. Hershey, PA: IGI Global.

\section{Published Version}

doi:10.4018/978-1-4666-2809-0.ch007

\section{Permanent link}

http://nrs.harvard.edu/urn-3:HUL.InstRepos:37678279

\section{Terms of Use}

This article was downloaded from Harvard University's DASH repository, and is made available under the terms and conditions applicable to Open Access Policy Articles, as set forth at http:// nrs.harvard.edu/urn-3:HUL.InstRepos:dash.current.terms-of-use\#OAP

\section{Share Your Story}

The Harvard community has made this article openly available.

Please share how this access benefits you. Submit a story.

Accessibility 
Why Immersive, Interactive Simulation Belongs in the Pedagogical Toolkit of "Next

Generation” Science: Facilitating Student Understanding of Complex Causal Dynamics

M. Shane Tutwiler

Harvard University, USA

Tina Grotzer

Harvard University, USA

\begin{abstract}
Demonstration and simulation have long been integral parts of science education. These pedagogical tools are especially helpful when trying to make salient unseen or complex causal interactions, for example during a chemical titration. Understanding of complex causal mechanisms plays a critical role in science education (e.g. Grotzer \& Basca, 2003; Hmelo-Silver, Marathe, \& Liu, 2007; Wilensky \& Resnick, 1999), but few curricula have been developed to expressly address this need (e.g. Harvard Project Zero, 2010). Innovative education technologies have allowed content designers to develop simulations that are both immersive and engaging, and which allow students to explore complex causal relationships even more deeply. In this chapter, the authors highlight various technologies that can be used to leverage complex causal understanding. Drawing upon research from both cognitive science and science education, they outline how each is designed to support student causal learning and suggest a curricular framework in which such learning technologies might optimally be used.
\end{abstract}

\title{
Introduction
}

“I just don't think you're thinking about all of the possible factors" the young engineer sighed as she opened a new word processing documents to take note of what her colleague was saying. Inez and Omar, partners on a city-planning project for their local municipality, were carefully reviewing their proposed development plans. Using advanced simulation software, 
each had independently modeled the effect of increased industrialization on pollution levels over time, and then predicted how these events might lead to further changes in their town's economy and demographics. They didn't exactly agree on the projected outcomes.

"It's clear as day!” Omar replied. "There was a link between number of factories and crime in my ten-year model. You can't deny that! I can make predictions about future trends based on that." Shaking her head, Inez calmly replied “I just don't think it’s that simple. You're saying it's a direct connection, when I don't think it is. Look, my model looked at one hundred years-worth of change, and crime values went up and down, even though the number of factories in the city was the same. I don't know...it's just not simple." In time, the two decided on a complex relationship relating industrialization to crime and population over time, and prepared their findings in a report to the city zoning board.

Later, the two were tasked with helping to gauge the impact of proposed construction in a small suburban community near the city. Residents wanted to build new houses and recreational areas such as a golf course near a popular pond. Using a sophisticated multi-user virtual environment to simulate the area, Inez and Omar, along with two other teammates, discovered a scenario in which many large fish in the pond all died in a short period of time due to an unknown cause. Dividing the work equally among the team, each member set out to collect data over time within the virtual environment. Comparing their notes and constantly revising their causal models, the team finally settled on a plausible scenario and advised the zoning board of possible hazards due to their planned construction.

When asked later to reflect upon these two project, Inez and Omar thought that they learned a lot, and that they helped them to think about problems as being more complex. They also said it was more fun than just sitting in class and listening to their teacher. Inez and Omar, 
you see, were eighth-grade students and had been using these simulations as part of problembased lessons in their science class throughout the year.

The vignette above is an example of how science students can interact with virtual simulations in meaningful and contextual ways. In these examples, students worked both independently and together to collect, synthesize, and analyze data as well as to develop and test hypotheses. Moreover, they took part in these endeavors in a curricular setting that embedded the simulations within meaningful and motivating contexts relevant to the subject matter and students. In this chapter, we outline research supporting this framing and give examples of commercial and research-driven technologies that can be used as such.

Demonstration and simulation have long been integral parts of science education. These pedagogical tools are especially helpful when trying to make salient unseen or complex interactions, for example during a chemical titration. Demonstrations allow the teacher to draw students' attention to variables that otherwise might be missed and to guide students towards the explanatory narratives of a concept. Simulations, for instance, Molecular Workbench ${ }^{\mathrm{i}}$ (Concord Consortium, 2004) or the PhET Simulations ${ }^{\text {ii }}$ (e.g. Wieman, Adams, \& Perkins, 2008), offer models of processes that cannot be directly observed—only inferred. These thoughtfully illustrated computer simulations are designed to illuminate particular processes such as conduction, osmosis, Ohm's Law and so forth. The combination of simulation and demonstration enables students to envision these processes and gain from the expertise of an instructor in understanding them.

For example, virtual simulations are fast becoming a staple of medical education, due to the rapid rate of technological advances and growing patient anxiety over experimental procedures. Okuda, Bryson, DeMaria, Jacobson, Ingram-Goble, Zuiker, and Warren (2009) 
found that studies of the difference between simulation-based and traditional medical education showed gains in procedural performance and adherence to protocols, increased medical knowledge, and increased re-test performance for subjects in the simulation groups. In a similar review of studies of such simulations in medical classrooms, Issenberg, Mcgaghie, Petrusa, Gordon, and Scalese (2005) determined that the best simulations provide feedback and the chance for repetition, were well integrated into the curriculum, offered a range of difficulties, and were valid representations of the scenario being simulated. Taken together, these reviews point toward a strong positive impact of embedding simulations in medical education.

Should we expect these results to transfer to general science learners, however? After all, medical school students are pre-screened based on their content knowledge and other traits such as flexible thinking and ability to handle stress. They are, in effect, much closer to being experts than novices in their domain than the general science learner. Do these simulations have equally beneficial effects on these types of learners? Research across domains and age-groups seems to suggest so.

Jimoyiannis and Komis (2001), for example, found that students using physics-based simulations showed better understanding of tasks related to velocity and acceleration when compared to a control group in a traditional lab setting. Furthermore, Zacharia (2006) demonstrated that students in virtual physics experiment groups showed higher overall learning gains than those in a traditional experiment group. Rutten, van Joalingen, and van der Veen (2012) also found that simulations could have an impact on learning, especially in lab-based scenario training, as long as the work was properly embedded in the curriculum and valid. Looking at learning in earth science, Barab, Scott, Siyahhan, Goldstone, Ingram-Goble, Zuiker, and Warren (2009) found that students in a contextualized virtual environment based simulation 
showed higher gains than students using textbook-based lessons; while Koray (2011) found that students using problem-based-learning and virtual simulations fared better on post-intervention achievement measures than peers in a didactic instruction group.

These findings indicate that there are identifiable benefits to supplementing instruction with virtual simulations in various science domains. However, the framing of these simulations is critically important. From the above examples, Barab and colleagues (2009) found that the contextualized simulations were most impactful and Koray (2011) found gains when the simulations were specifically part of a problem-based-learning curriculum. In addition, Blake and Scanlon (2007), indicate that simulations such as these should contain student support, give multiple representations of concepts, and should be tailored to the learning needs of the students using them. Similarly, within the domain of chemistry, Kahn (2010) found that simulations were most effective when used in conjunction with a sound curricular development process.

Structuring of the problem space is also an important factor to consider when using virtual simulations. Shin, Jonassen, and McGee (2003) explored the types of knowledge, skills, and attitudes at play when students were presented with well-structured and ill-structured astronomy simulation tasks. When the problem was well structured, student domain knowledge and justification skills were significantly related to learning outcomes. However, students using simulations in an ill-structured problem space showed significant relationships between domain knowledge, justification skills, science attitudes, and cognitive regulation. In effect, students in messy data-spaces had to use more cognitive resources to learn and they had to call upon varied cognitive resources than students working in routine or highly structured problem spaces.

Another factor to consider when implementing virtual simulations into science classrooms is how the students themselves will interact with the technology, and whether or not 
that interaction might favor one type of student over another. Lin, Tutwiler, and Chang (2011) found that females in their study reported using virtual environments in the past differently than their male peers. The interaction effect between these two factors, gender and prior use, had a positive and significant relationship with post-intervention learning when controlling for pre-test scores; in other words, girls who reported playing more video games in the past outscored their female peers who reported playing fewer video games, as well as their male peers in the frequent past-play group (Lin et al, 2011). These results were mirrored in another study, in which boys were able to complete a simulated escape from a burning building faster than girls. The time of that trial was then shown to be a significant predictor of performance on a knowledge test related to lessons learned in an unrelated virtual environment (Lin, Tutwiler, \& Chang, 2012). In effect, student comfort of navigation within the simulation was gender-biased, and that ability to navigate was related to learning gains in other virtual environments. It is important to note that these studies were conducted in Taiwan, where student use of virtual environments outside of the classroom (i.e. video games) may differ from students of other cultures, as may the class environment and student motivation to perform well on assessments (such as those given during the course of the research). That being said, the trend points towards the need for careful planning and implementation in all settings where students may interact with virtual worlds. In sum, these findings point toward a positive relationship between the use of virtual simulations and science learning. It is important to remember, however, that these positive impacts come with myriad qualifiers. The simulations must be appropriately integrated (Issenberg et al, 2005; Kahn, 2010; Rutten et al, 2012), contextualized (Barab et al, 2009), provide maximum benefit when part of a problem-based lesson (Koray, 2011), implemented with 
student prior use of technology in mind (Lin et al, 2011), and are often most strongly associated with performance-based outcomes (Rutten et al, 2012; Okuda et al, 2009).

Simulations of this type combined with demonstration are important tools in science education and will continue to play a role in engendering deep understanding in science. However, in this chapter, we argue that immersive and interactive simulations are critical to the pedagogical toolkit of "next generation" science education and that they can play a key role in helping students learn the causal dynamics of a complex world. Increasingly, scientists need to be able to reason well about complex systems dynamics—extending beyond direct, spatially and locally immediate one to one correspondences. These dynamics may entail emergence, time delays and spatial gaps, non-linearities, extended indirect patterns, and so forth (Grotzer, 2004; forthcoming). In the paragraphs to follow, we make the case that simulations that have interactive and immersive qualities invite consideration of complex causal dynamics and the opportunity to reveal and revise our causal assumptions. We offer an illustration from a commercially available computer game of how simulations become more than computer games with the right set of accompanying pedagogical moves.

Research shows that without opportunities to learn the embedded causalities in scientific phenomena, students do not progress towards more expert conceptions (Hmelo-Silver, Marathe \& Liu, 2007; Perkins \& Grotzer, 2005). They are likely to default to simpler patterns (Driver, Guesne \& Tiberghien, 1985; Grotzer, 2004; Raia, 2008) and to miss the inherent dynamics driving the broader systems outcomes. Further, people of all ages are typically unaware of their causal default assumptions or the role that they play in distorting scientific concepts and expert grasp of dynamic systems (e.g. Dorner, 1989; Grotzer \& Lincoln, 2007). Many of the greatest 
ecological disasters are instantiations of this phenomenon (Grotzer, forthcoming; Walker \& Salt, 2006).

A growing body of research calls for creating opportunities and the accompanying pedagogies for students to learn the embedded causal complexities involved in understanding the world as a systematic, integrated, and global entity. This work acknowledges that teaching reductionist, clockwork approaches to complex organic and emergent phenomenon (Jacobson, 2001) is a dangerous precedent and that we need new approaches and pedagogies to make this shift (Grotzer, Dede, Metcalf, \& Clarke, 2009; Hmelo-Silver \& Azevedo, 2006). Research has also suggested that new pedagogies can build upon students' existing knowledge from their experiences in the world to formalize and expand these understandings. For instance, Levy and Wilensky (2008) studied sixth grade students' understanding of scattering behavior in gym class in an exploration towards its use in science class.

Innovative education technologies have the potential to enable simulations that invite complex systems reasoning. For instance, NetLogo ${ }^{\text {iii }}$ and StarLogo ${ }^{\text {iv }}$ both offer ways to experiment with organic emergent causalities, to explore outcomes on the basis of individual agents or population levels, and to contrast the two. Students program a set of turtles that interact in parallel giving rise to population outcomes. The outcomes are often very surprising and difficult to imagine based upon the simple rules programmed at the individual level. Danish, Peppler, Phelps and Washington (2011) introduced a wearable simulation called BeeSim to help kindergarten students learn about the systematic, decentralized behavior in a bee hive connecting their own actions (as a bee) to the individual and hive outcomes. The simulation attempts to address one aspect of what students have struggled with in thinking about decentralized 
causality—reasoning in different levels (Wilensky \& Resnick, 1999) between individuals and populations.

Virtual environments (VEs) extend these experiences further. Dede, Grotzer and colleagues (Grotzer, Dede, Metcalf, \& Clarke, 2009; Metcalf, Kamarainen, Tutwiler, Grotzer, \& Dede, 2011) have advanced the idea that VEs can invite students to grapple with complex causal patterns in powerful ways by offering real world vignettes that are problem-based. VEs, both those designed specifically for use in classrooms and those designed for commercial use but adopted into a specific curriculum, have been used for a multitude of educational purposes (Dieterle \& Clarke, 2007; Squire, 2003). As in the examples above, VEs are highly interactive and enable students to use their own actions to learn about the systems dynamics in play. However, through their virtue of being both immersive and interactive (Dede, 2009), they invite students to play out their causal default assumptions as they might in the real world, to experience the consequences, and to revise their assumptions towards more effective outcomes. They have the potential to address what causal relationships students perceive, attend to, and reason about in the virtual world, and this as we elaborate below, is a significant step towards better complex causal reasoning and action in the next generation.

Specific affordances can be built into VEs, such as the ability to zoom in and out to view the system at various levels, move backwards and forwards in time, and to receive graphical feedback about system changes makes VEs an ideal platform for helping students to understand the underlying structure of complex causal systems (Grotzer et al. 2009; Metcalf et al., 2011). Below, we illustrate how immersive simulations can reveal, leverage, and build complex causal understanding through exploring a specific example. Through this example, we build the case 
for immersion and interactivity and consider how teacher guidance can facilitate students' productive engagement towards the goals of learning the complex causal dynamics.

In the following paragraphs, we describe how one commercially produced VE, SimCity ${ }^{\mathrm{TM}} 4$, can be used to frame and support the learning of more expert complex causal patterns in middle- to high-school students. The following sections describe SimCity ${ }^{\mathrm{TM}} 4$ and the initial preparation that enables the students to engage in the vignette as follows, and how the simulation invites students to uncover various complex causal patterns. We unpack the specific complex causal patterns underlying the observed outcomes and detail points during which the teacher can provide support. Finally, we address some shortcomings inherent to the use of SimCity ${ }^{\mathrm{TM}} 4$, and discuss the development of a multi-user virtual environment that more fully leverages the possibility of immersion and interactivity to enable learning of sophisticated causal dynamics.

\section{An overview of SimCity 4}

Imagine that you live in a town of 30,000 people, and the population has been in a steady

decline over the last decade, a scenario not uncommon in some mid-western cities. One proposed plan to reverse this trend and revitalize the community is to increase the industrial profile of the municipality, in the hopes of luring families to work in the new factories, thus bringing tax revenues back to previous levels, allowing your city to sustain services such as parks and recreations. The relationship seems very straightforward: more jobs, means more people, which equals more money for the city.

Unfortunately, things don't exactly work out as the town administration had planned. Within five years, housing prices have dropped, people are leaving the city again, and 
satisfaction with the administration is at an all-time low. Why didn't the simple model predict these trends? What causal relationships actually led to these negative outcomes?

This scenario is a common example of the over-simplification of a complex causal system that has its parallels in abundant planning and ecological examples (See for instance, Dorner, 1989; Grotzer, forthcoming; Tenner, 1996). Interestingly, it also has parallels in the learning of many science concepts, such as air pressure, density, geology, or the motion of electrons through a circuit (Driver, Guesne, \& Tiberghien, 1985; Feltovich, Spiro \& Coulson, 1993; Grotzer, 2004; Raia, 2008) given the common reasoning patterns that give rise to them. For instance, students typically ascribe a simple linear model to sinking and floating, by attributing the outcome solely to the weight of the object instead of realizing that the relationship between the density of the liquid and the density of the object account for the outcome (Perkins \& Grotzer, 2005). Similarly, they reason that if all the green plants were to disappear, it would impact the primary consumers but not the secondary consumers (Grotzer, 1993; White, 1997) However, this scenario is actually from a commercial computer game, SimCity ${ }^{\mathrm{TM}} 4$. Depending upon how the game is used, it has the potential to reveal students' initial default assumptions and to model more complex causal dynamics—ones that students might at first think are simple.

Released in 2003 by software company Maxis, developers of other popular simulation games such as The Sims franchise, SimCity 4 (henceforth SimCity) is the most recent incarnation of the popular SimCity series that began in 1989 (Electronic Arts, 2011). In SimCity, players are able to plan and build cities by zoning areas as residential, commercial, or industrial. As their city's population grows, the player, acting as mayor, must decide how to allocate resources and upgrade existing infrastructures to induce growth, or to keep population at a given level, all while maintaining positive reviews from the virtual denizens of the city, the Sims. 
The game itself was designed purely for entertainment purposes, and as such is not intended to be a true urban planning simulator or a means to teach complex causal patterns. Devisch (2008) outlined multiple ways in which the assumptions underlying the game's design do not make it a high-fidelity simulation. However, the underlying causal patterns are present and identifiable, and represent a scaled-down version of the complex interactions that underlie the social and environmental spheres of urban growth. Here, we suggest ways in which SimCity can be initially staged and used to offer a virtual simulation experience, that engages students with the underlying complex causal structures as well as how teachers can support student learning thereof.

\section{The Interactive Simulation: Industry Overload}

Overview of a Productive Learning Path and Comparisons to Explore

Our interactive simulation in SimCity ${ }^{\mathrm{TM}} 4$ Deluxe centers on the effects of a rise in industrial zoning on pollution levels, city population, and mayoral popularity within SimCity. ${ }^{\mathrm{v}}$ The Large City training scenario positions the student (or students, if playing in groups) as the newly appointed mayor of the demonstration city. In an effort to lure new people to the city, they've been tasked by the city council with building new industrial zones. The hope is that new industrial jobs will entice people to move to the city.

In order to set students up to notice the causal dynamics, teachers can engage them in some specific population predicting exercises. Students would pause the game and designate all unzoned areas on the map as industrial zones (Figure 1, below). Then, they would make predictions about how this will affect the city's population in one, five, and ten year intervals, as well as explain the mechanism as to why population will change as they predict. They might, for 
example, draw a map of the city and show where they think population will change the most, and where air and water pollution changes might occur.

\section{[Insert Figure 1 here.]}

From here, the students can set the game to maximum speed (“cheetah mode”) and observe the city’s population (and population density), pollution levels (and location), and mayoral popularity via the embedded graphical data displays (Figures 2-4, below). Over the course of ten in-game years, students should pause the game at six-month intervals and make observations of each of those values, and then assess whether these trends matched their predictions. If not, they would note points of deviation, and reflect upon why this might be the case.

[Insert Figure 2 here] [Insert Figure 3 here] [Insert Figure 4 here]

Next, the student(s) can reset the scenario and re-zone the industrial areas as before, and let the game play through on cheetah mode, this time taking measurements at yearly intervals for ten years. Do they think the values of their data will be the same as the first ten-year period? Comparing these one-year intervals to those of their first trial, and reflecting upon why they might be different will engage students in thinking about the differences between their zoning decisions in change over time.

Finally, students can reset the scenario and make no changes to the number of industrial zones, and take the same set of yearly measurements over a ten year in-game period. This offers a counter-factual condition (Rubin, 2005), and gives an example of what might have happened to the system had the mayor (student) not intervened and re-zoned. We seldom have access to counterfactual conditions in the real world so this is an important affordance that simulations can 
provide for learning about causal dynamics. How do these values compare to those collected from their first two trials? Why might they be different?

Timely assessment and feedback of student understanding is a critical component of the simulation. In order to facilitate this continuous assessment/feedback cycle, the teacher should ideally circulate amongst students or groups as much as possible, observing and asking students what changes they notice in the system over time. One strategy for helping students to recognize the longitudinal changes, while also assessing their understanding, is through the use of guided questions. For example, a teacher might play the role of “wise fool” and pretend that they don't fully understand the interface. They could ask students to show how population density is displayed, and in doing so, ask follow up questions about the relationship between the density and other factors. Student actions and responses can then be evaluated for understanding of underlying concepts.

In addition to the in-process changes within each trial, it is also important that student comparisons of the differences and similarities between each trial be assessed. These differences in trends form the basis for recognizing specific forms of complex causal relationships, outlined below. One method for conducting such assessment might be to embed it within a situated context (Lave \& Wenger, 1991). For example, students can be assigned the role of “city planner", and act as an advisor to the mayor (the teacher). Their task, then, is to use advanced simulation software (SimCity) to evaluate the possible outcomes of the mayor's plan to increase industrialization in order to increase municipal revenue and population. The planners (students) are then tasked with developing lists of pros and cons for the proposal, and presenting these findings to the mayor at the end of the project through written or oral reports (or a combination of both). It is during the course of completing and reflecting upon the assignment, then, that 
students begin to recognize complex causal patterns, the existence of which should be noted in said reports.

Table 1, below, summarizes the steps detailed above.

Table 1. Outline of conditions, steps, and suggested teacher support for using SimCity to model various causal complex patterns

\begin{tabular}{|c|c|c|}
\hline Condition & Steps & Teacher support \\
\hline & $\begin{array}{l}\text { 1. Pause game and designate } \\
\text { free zones as "industrial” }\end{array}$ & \\
\hline \multirow[t]{2}{*}{ Prediction } & $\begin{array}{l}\text { 2. Predict population and } \\
\text { crime levels one, five, and ten } \\
\text { years into the simulation }\end{array}$ & $\begin{array}{l}\text { Question students about what } \\
\text { factors led to their specific } \\
\text { predictions }\end{array}$ \\
\hline & $\begin{array}{l}\text { 1. Reset the scenario and } \\
\text { designate all free zones as } \\
\text { "industrial" }\end{array}$ & \\
\hline \multirow[t]{4}{*}{ First Trial } & $\begin{array}{l}\text { 2. Set game speed to "cheetah } \\
\text { mode" }\end{array}$ & \\
\hline & $\begin{array}{l}\text { 3. Pause the game at six } \\
\text { month intervals and take } \\
\text { measurements }\end{array}$ & $\begin{array}{l}\text { Ask students to show how } \\
\text { each measurement is made, } \\
\text { and what they notice }\end{array}$ \\
\hline & $\begin{array}{l}\text { 4. Assess if values matched } \\
\text { predictions }\end{array}$ & $\begin{array}{l}\text { Ask why the value did/did not } \\
\text { match }\end{array}$ \\
\hline & $\begin{array}{l}\text { 1. Reset the scenario and } \\
\text { designate all free zones as } \\
\text { "industrial" }\end{array}$ & \\
\hline \multirow[t]{4}{*}{ Second Trial } & $\begin{array}{l}\text { 2. Set game speed to "cheetah } \\
\text { mode" }\end{array}$ & \\
\hline & $\begin{array}{l}\text { 3. Pause the game at one year } \\
\text { intervals and take } \\
\text { measurements }\end{array}$ & $\begin{array}{l}\text { Ask students to show how } \\
\text { each measurement is made, } \\
\text { and what they notice }\end{array}$ \\
\hline & $\begin{array}{l}\text { 4. Assess if values matched } \\
\text { predictions }\end{array}$ & $\begin{array}{l}\text { Ask why the value did/did not } \\
\text { match }\end{array}$ \\
\hline & $\begin{array}{l}\text { 1. Reset the scenario but } \\
\text { don't rezone any areas }\end{array}$ & \\
\hline
\end{tabular}


Counterfactual

2. Set the game speed to

"cheetah mode"

3. Pause the game at one year

Ask students to show how intervals and take each measurement is made, measurements and what they notice

How the Interactive, Immersive Simulation Enables Engagement with Complex Causal

\section{Dynamics}

Students’ simplifying assumptions about the nature of complex causal relationships are revealed in their initial simple and linear predictions about the relationship between increased industrial zoning and population, pollution, and popularity. Through engaging in the simulation and teacher guidance, students have the opportunity to reflect upon the nature of the causal relationships that led to their observed data. Here we outline what the process of engaging with the complex causal features looks like through the lens of how a prototypical student proceeds through the simulation, observing changes. We discuss what complex causal patterns are responsible for those observed changes and offer examples for how teachers can facilitate student understanding of each.

The student begins by designating new industrial zones as detailed above, and as directed by the teacher. Every empty plot of land is quickly filled, and as the student un-pauses the game, she notes that activity quickly ensues in the affected areas. As time passes in-game, the density of industrial buildings rises, as the zoned areas fill. As expected, the city's population begins to rise.

However, as the student collects the requisite data at the designated annual or semiannual points, she cycles through a few other graphs and notices that housing prices (measured in SimCity as the “desirability” of given residential plots) are beginning to fluctuate as well. 
Initially, she notices a spike, as the population begins to grow. But, as the population stabilizes, housing costs begin to fall, even as the density of industrial buildings continues to increase. In essence, it appears to the student that an increase in the number of industrial buildings in one area coincides with decreasing housing costs in a non-adjacent area, over time.

This is an instance of a spatiotemporally distant causal pattern. Many causal relationships involve a spatial delay, a temporal delay, or both, between the occurrence of the causal event and the perceived effect. For example, greenhouse gas emission in centrally located continents has contributed to the gradual warming of the arctic region over time. Research has shown, however, that people expect causes to fall in close spatiotemporal proximity to their effects, or vice versa (e.g. Grotzer, forthcoming).

Seeing that the student is confused, her teacher instructs her to compare the desirability data from her two intervention simulations with her control simulation. The connection is clear: increased industrial activity in one area leads to lower housing prices in another after a period of time.

Having recognized the connection between growth in the industrial sector and decreased desirability of distant homes over time, the student then begins to formulate hypotheses as to why. Her initial hypothesis is quite direct and encompasses only those two variables, degree of industrialization and desirability of homes, without taking into account any other mitigating factors. This relationship has a simple linear causal structure (Grotzer, 2004). However, the student quickly realizes that she can't explain why the two areas, quite separate on the map, would have such a relationship.

It is at this point that the teacher can facilitate exploration of more complex dynamics by asking the student to make a list of other variables measured in SimCity, but not initially 
measured during the three simulations, that might also make home prices drop. Crime, for example, is one of these variables. The student could then re-run a simulation with increased industrial zones (similar to simulations 1 and 2), and note the crime map (Figure 5, below) and crime graph (Figure 6, below) yearly. The eventual dip in housing prices was preceded by a rise in crime spurred by the spike in industrial zones. This is, in effect, a non-linear causal relationship known as domino causality (Grotzer, 2004).

[Insert Figure 5 here, please] [Insert Figure 6 here, please]

It is important to understand non-linear causal patterns such as domino causality, because very few causal relationships outside of tightly controlled laboratory studies or simple physical causal systems (such as hitting a baseball with a bat) are truly linear. In fact, it has been argued that much of the historic progress made in hard sciences, such as physics, involves making increasingly more detailed observations in order to better account for the intervening causal connections between relationships that appear to occur as action at a distance (Lange, 2002).

Later, as the student looks back over her collected data, she notices another interesting pattern. The mass industrial re-zoning took place all at once, at the beginning of the simulation. So, the density of industrial buildings rose over the course of the simulation, quickly at first, and less near the end, but it generally increased at each measurement. However, some values, such as pollution, population, and mayoral popularity go through long stretches of constancy before finally changing.

This is an example of steady state causality, in which the system is in dynamic balance or the process occurs undetected over time until registering a perceivable change. Recognizing this causal pattern is important because many causal systems are in a steady state most of the time. For example, a laptop computer sitting on a wooden desk is exerting a downward force on the 
table top (weight), while the table pushes back, in the opposite direction, with an equivalent force (normal force). This system is in a steady state. However, were the desk's structural integrity to become compromised (perhaps by termites), it would no longer be able to apply the appropriate normal force to the computer, and the computer would fall through. This, in turn, would trigger a shift from steady state to event based causality, which students are more likely to perceive (Chi, 1997; Grotzer, 2004).

However, more expert causal conceptions recognize steady states in addition to eventbased causality—-thus it is undesirable that students only recognize causal connections during or after a system collapse. In SimCity, students can be supported in their understanding of steady state causality by having them restart the scenario and play the game at "normal” speed. By measuring changes on a day-to-day or even week-to-week basis, and comparing the rate of change to that of the annual or semi-annual measurements taken before, students will quickly see that values tend to be stable for long stretches of time.

Finally, the student notices that the values measured in the original two simulations in which maximum industrial zones were placed are not exactly the same. Her teacher encourages her to think about why this might be, and the student decides that it might be because, even though she tried very hard to make both conditions exactly the same, she might have placed different amounts of industrial zones in each, but she’s not sure how she can tell. Her teacher then asks about the other scenario, in which no extra industrial zones were added. The student decides to run that simulation once more, at cheetah speed, and take bi-annual measurements as before. Surprisingly, the numbers do not exactly match those from her first control trial, although they are close. The student then realizes that making changes to the game world does not directly 
cause the Sims to behave in a particular way, it only increases or decreases the possibility that they will.

This is an example of probabilistic causality, in which the causal relationship between two or more variables is not deterministic. It is important to understand this complex causal pattern because in science, effects do not always reliably follow a given cause. For example, smoking does not always cause lung cancer; it only increases the likelihood that a person will develop lung cancer over time. Students with a deterministic conceptualization of a causal relationship, on the other hand, might miss the existence of a causal link if the cause does not lead to the effect in every instance (Grotzer, Duhaylongsod, \& Tutwiler, 2011)

In our example, the student's understanding of this pattern is leveraged by specifically drawing her attention to the differences between their two sets of data, and to reflect on what might account for them. At first she guesses that facets of measurement error are to blame, but these can be controlled for, to a point, by having the student place the exact same number of industrial zones, and collect data on the exact same days in each trial. Ultimately, can she say with certainty exactly what the critical measurements will be at any given time, even though she was in control of placing the original causal agents (the industrial zoned areas)? If not, then the relationship, while causal, is probabilistic.

Our description of a SimCity-based curriculum offers a sense of what an "off the shelf” interactive, immersive program can offer students in terms of learning to reason about causal complexity. It is important to keep in mind the myriad scaffolds in place, however. Simply giving the game, which will likely be engaging and novel at first, to teachers and asking them to have their students play it is unlikely to lead to increased student causal understanding. We recommend that interested teachers first play through each scenario, so as better to anticipate 
problems and questions the students might have. This step, having teachers interact with the virtual simulation (or any technology being integrated), is critical but often overlooked due to time or resource constraints.

The promise of such technology can be more fully realized if the software is designed from the ground up to reflect expert modes of engagement with the causal dynamics and the many affordances that can be built in to leverage students' exploration and to reveal to them the inadequacy of reductive causal models. Dede, Grotzer, and colleagues have built and are testing EcoMUVE, a VE funded by the Institute of Education Sciences. EcoMUVE was designed to teach ecosystem science concepts and to help students develop more expert patterns of scientific reasoning about the causal dynamics within ecosystems. Students using the EcoMUVE take part in two one-week curricula embedded within a virtual world. In the first, they work together as specific types of scientists in teams to discover why all of the large fish in a pond ecosystem died. In the second, students again work in groups to explore predator-prey relationships between wolves and deer on various islands. Both modules leverage the strengths of interactive, immersive simulations, like SimCity, but they also include design elements that better allow students to detect complex causal patterns from observational data.

For example, in both modules students in EcoMUVE are able to use a Calendar Tool (Figure 7, below) to move back and forth in time at will to make repeated observations. In the case of the pond module, this will allow students to measure and verify critical chemical levels and other key indicators of ecosystem health over time. In the forest module, students will be able to take more nuanced measurements of animal populations as well as explore certain aspects of the terrestrial ecosystem in more detail. In SimCity, however, the student had to reset the scenario and play through again, collecting data at designated points in time, if they wanted to re- 
observe a relationship. This ability to treat time more flexibly will make it more likely that students will detect changes in the VE over time, a critical part of understanding the complex nature of ecosystems.

In addition, EcoMUVE includes a data graphing tool (Figure 8, below) that allows students to compare trends in multiple variables over time. Managing data salience is a critical part of scaffolding student understanding of complex systems (Grotzer, forthcoming). By giving students a way to make salient individual datum, then compare sets of data in a meaningful way, the EcoMUVE supports such learning. This is in contrast to SimCity, which allows for the viewing of a single variable at a time.

Building such affordances into an interactive and immersive environment appears promising. Preliminary results indicate that students using the EcoMUVE made significant gains in their understanding of spatiotemporally distant causal relationships (Metcalf et al, 2011) and processes and steady states (Grotzer et al. 2011).

[Insert Figure 7 here] [Insert Figure 8 here]

A final affordance of MUVEs over their commercial cousins is that they can be design with back-end data collection protocols that allow for both research as well as substantive feedback to educators using the system. For example, River City, an educational MUVE that was the technological inspiration for the EcoMUVE collected and reported student chat logs to the teacher each day that students used the system. A similar function in the EcoMUVE could be combined with automatic data-mining algorithms that look for phrases indicative of causal misunderstandings as well as strengths. Also, student movement (Dukas, 2009) and data collection (Clarke, 2009; Ketelhut, 2007) were analyzed in River City, and similar analyses can 
be performed in the EcoMUVE, both for research purposes as well as feedback for teachers on student causal learning.

For example, student pathing (the patterns of areas they visit in the VE) can indicate if a student is attending to distal vice proximal causes. In addition, the order and rate at which they collect data, and what tools they use to do so, might also give us insight into their understanding of the VE as a complex ecosystem. In its final implementation, these data can be summarized and reported to help the teacher better understand student learning over the course of the curriculum.

\section{Conclusions}

We have argued here for the importance of including immersive and interactive simulations in the pedagogical repertoire of "next generation science" and that these simulations have a special role to play in teaching the nature of dynamic, complex causal systems. We have offered an example from "off the shelf" software of how such simulations can invite students to rethink their causal assumptions — what they perceive and attend to in an environment and how

they reason about it. In framing this example, we ensured that the simulation was immersive and interactive by being appropriately integrated (Issenberg et al, 2005; Kahn, 2010; Rutten et al, 2012), contextualized (Barab et al, 2009), part of a problem-based lesson (Koray, 2011), and that the student was provided the appropriate scaffolds and supports from the teacher (Blake \& Scanlon, 2007).

In the example here, we included teacher support and how it might facilitate students' deepening understanding of more expert forms of reasoning about causal complexity. The level of teacher guidance has been studied in other forms of simulations. For instance, Paulson, Adams and colleagues (Adams, Paulson, \& Wieman, 2009; Paulson, Perkins, \& Adam, 2009) 
have contrasted no guidance, driving questions, gently guided, and strongly guided interactions with simulations found that no guidance or driving questions was most effective. However, we consider this an important area for study in immersive, interactive simulations given that unless driven to do so by problem-based content or guiding questions, students may be likely to fall into the same simplifying default patterns as in the real world. Further, we acknowledge that teachers are prone to similar simplifying assumptions. Supplying teachers with the necessary pedagogical content knowledge and understanding of expert epistemologies would be critical to the successful use of the simulations. In the case of the SimCity scenario proposed here, that includes having the teacher play through the scenarios and make note of trends they see before using it with their students.

Work in progress that is specifically designed to leverage the affordances of interactive and immersive technology (Dede, 2009), such as EcoMUVE, signal the promise of such simulations and argue for their place alongside other forms of simulation in science education. We caution that, as designers develop, test, and implement these immersive environments, care should be taken such that factors outside of the classroom, such as prior access and use of similar technologies, are accounted for (Lin, et al, 2011). Future work in this problem space will include detailed observation and analysis of student complex causal learning longitudinally, explorations of the relationships between prior causal knowledge and student data-gathering behavior in the causal environments, and the effect of data salience and complexity on student causal learning.

An important issue that remains to be addressed is that of transfer to real world environments. Given the rich research literature in cognitive science that shows that transfer is not straightforward and requires explicit attention and scaffolding (Perkins \& Salomon, 1988), it is important to consider the challenges of mapping from a virtual world to a real one. Goldstone 
and Sakamoto (2003) have found that the closer the features of the virtual world fit with those of the real world, the more likely that students will be cued to the likelihood of transfer. Unfortunately, more similarity in surface features also makes it less likely that students will learn to understand the embedded deep structures—in this case, the causal complexities—deeply. The impact seems to be stronger for students who perform less well in school.

Further, the issue of transfer is more difficult when we are seeking informed action, not just better reasoning. One may be well inclined to engage in actions that are easy to take in a virtual world and yet these may have little chance of being sustainable in a real world where more effort needs to be invested to enact that action. One vivid example of this is the study by Lin et al (2012), in which high-school aged boys and girls were asked to escape from a simulated burning building in a virtual world. Though the girls and boys acted differently in the real world, with boys being more willing to take risks resulting in a lower average escape time (Lin et al, 2012), there is no reason to believe that they would have taken the same actions in the real world, when true danger was perceived. Instead, all students would likely have chosen the route perceived to be most safe.

We expect that as powerful computing devices become ubiquitous, these devices can be leveraged to simulate complex causal dynamics. Enabling students to have an immersive and interactive experience allows them to engage with and reflect on the causal outcomes in ways that will demand their attention to the inherent complexity. Combining these technological affordances with productive pedagogies should enable powerful lessons for living more effectively in a complex world.

\section{Acknowledgements}


We would like to express our appreciation to our colleagues, Chris Dede, Shari Metcalf, and Amy Kamarainen as well as to the anonymous reviewers and to Dr. Myint Khine and Dr. Issa Saleh. We would also like to thank Lynneth Solis and Leslie Duhaylongsod for helping us to evaluate and think about student complex causal learning. Finally, we would like to thank the editors of this volume for their limitless patience and guidance as we worked to craft this chapter.

This work was supported in part by the following awards: Causal Learning in the Classroom Studies supported by Grant No. NSF-0845632 from the National Science Foundation, to Tina Grotzer; EcoMUVE Project supported by the Institute of Education Sciences, U.S. Department of Education, Grant No. R305A080514 to Chris Dede and Tina Grotzer; and EcoMOBILE Project supported by Grant No. NSF-1118530 to Chris Dede and Tina Grotzer. Any opinions, findings, conclusions or recommendations are those of the authors and do not necessarily reflect the views of the National Science Foundation or the Institute for Education Sciences.

\section{References}

Adams, W.K., Paulson, A. \& Wieman, C.E. (2009). What levels of guidance promote engaged exploration with interactive simulations? , PERC Proceedings.

Barab, S.A., Scott, B., Siyahhan, S., Goldstone, R., Ingram-Goble, A., Zuiker, S., Warren, S. (2009). Transformational play as a curricular scaffold: Using videogames to support science education. Journal of Science Education 18(4), 305-320.

Blake, C, \& Scanlon, E. (2007). Reconsidering simulations in science education at a distance: features of effective use. Journal of Computer Assisted Learning 23(6), 491-502. 
Chi, M.T. H. (1997). Creativity: Shifting across ontological categories flexibly. In T.B. Ward, S.M. Smith, \& J. Vaid (Eds.) Creative thought: An investigation of conceptual structures and processes (pp. 209-234). Washington D.C.: American Psychological Association.

Clarke, J. (2009). Exploring the complexity of inquiry learning in an open-ended problem space. Unpublished Doctoral Dissertation, Harvard Graduate School of Education.

Danish, J., Peppler, K., Phelps, D., \& Washington, D. (2011). Life in the hive: Supporting inquiry into complexity within the zone of proximal development. Journal of Science Education and Technology, 20(5) 454-467.

Dede, C. (2009). Immersive interfaces for engagement and learning. Science, 323(5910), 66-69.

Devisch, O. (2008). Should planners start playing video games? Arguments from SimCity and Second Life. Planning Practice \& Theory, 9(2) 209-228.

Dieterle, E., \& J. Clarke. (2007). Multi-user virtual environments for teaching and learning. In Encyclopedia of multimedia technology and networking, 2nd, ed. ed., M. Pagani, 103344. Hershey, PA: Idea Group, Inc. Press.

Dorner, D. (1989). The logic of failure: Why things go wrong and what we can do to make go right. NY: Metropolitan Books.

Driver, R., Guesne, E., \& Tiberghien, A. (Eds.) (1985). Children's ideas in science. Philadelphia: Open University Press.Electronic Arts (2011). SimCity ${ }^{\mathrm{TM}} 4$ Deluxe Edition. Retrieved on 4 December, 2011 from http://www.ea.com/simcity-4-deluxe

Dukas, G. (2009). Characterizing student navigation in educational multiuser virtual environments: A case study using data from the River City project. Unpublished Doctoral Dissertation, Harvard Graduate School of Education. 
Feltovich, P. J., Spiro, R. J., \& Coulson, R. L. (1993). Learning, teaching, and testing for complex conceptual understanding. In N. Frederiksen \& I. Bejar (Eds.), Test theory for a new generation of tests (pp 181-217), Hillsdale, NJ: LEA.

Goldstone, R.L.\& Sakamoto, Y. (2003). The transfer of abstract principles governing complex adaptive systems, Cognitive Psychology 46, 414-466.Grotzer, T.A. (1993). Children's understanding of complex causal relationships in natural systems. Unpublished doctoral dissertation. Harvard University, Cambridge.

Grotzer, T.A. (2004). Putting science within reach: Addressing patterns of thinking that limit science learning. Principal Leadership, October, 2004.

Grotzer, T.A. (forthcoming). Learning causality in a complex world: Understandings of consequence. Lanham, MD: Rowman \& Littlefield.

Grotzer, T.A., \& Basca, B.B. (2003) Helping students to grasp the underlying causal structures when learning about ecosystems: How does it impact understanding? Journal of Biological Education, 38(1)16-29.

Grotzer, T.A. Dede, C., Metcalfe, S., \& Clarke, J. (2009, April). Addressing the challenges in understanding ecosystems: Why getting kids outside may not be enough. National Association of Research in Science Teaching (NARST) Conference, Orange Grove, CA, April 18, 2009.

Grotzer, T.A. \& Lincoln, R. (2007). Educating for “intelligent environmental action” in an age of global warming. In Moser, S.C. \& Dilling, L. (eds.) Creating a climate for change: communicating climate change and facilitating social change. New York: Cambridge University Press. 266-280. 
Grotzer, T.A., Duhaylongsod, L. \& Tutwiler, M.S. (2011, April). Developing explicit understanding of probabilistic causation: Patterns and variation in young children's reasoning. American Educational Research Association (AERA) Conference, New Orleans, LA, April 10, 2011.Grotzer, T.A., Tutwiler, M.S., Dede, C. Kamarainen, A., \& Metcalf, S. (2011, April). Helping students learn more expert framing of complex causal dynamics in ecosystems using EcoMUVE. Presented at the National Association of Research in Science Teaching (NARST) Conference, Orlando, FL. (April 4, 2011).

Hmelo-Silver, C. E., \& Azevedo, R. (2006). Understanding complex systems: Some core challenges. Journal of the Learning Sciences, 15, 53-61.

Hmelo-Silver, C. E., Marathe, S., \& Liu, L. (2007). Fish swim, rocks sit, and lungs breathe: Expert-novice understanding of complex systems. Journal of the Learning Sciences, 16, 307-331.

Issenberg, S.B., Mcgaghie, W.C., Petrusa, E.R., Gordon, D.L., Scalese, R. (2005) Features and uses of high-fidelity medical simulations that lead to effective learning: a BEME systematic review. Medical Teacher 27(1), 10-28.

Jacobson, M. J. (2001). Problem-solving, cognition, and complex systems: Differences between experts and novices. Complexity 6(3), 41-49.

Jimoyiannis, A., Vassilis, K. (2001). Computer simulations in physics teaching and learning: a case study on students' understanding of trajectory motion. Computers \& Education, 36(2), 183-204. 
Kahn, S. (2010). New Pedagogies on Teaching Science with Computer Simulations. Journal of Science Education and Technology 20, 215-232.

Ketelhut, D.J. (2007). The Impact of Student Self-efficacy on Scientific Inquiry Skills: An Exploratory Investigation in River City, a Multi-user Virtual Environment. Journal of Science Education and Technology 16(1), 99-111.

Koray, O. (2011). The effectiveness of problem-based learning supported with computer simulations on academic performance about buoyancy. Energy Education Science and Technology Part B-Social and Educational Studies 3(3), 293-304.

Lange, M. (2002). An Introduction to The Philosophy of Physics: Locality, Fields, Energy, and Mass. Oxford, UK: Blackwell Publishing.

Lave, J., \& Wenger, E. (1991). Situated learning: legitimate peripheral participation. New York: Cambridge University Press.

Levy, S.T. \& Wilensky, U. (2008). Inventing a "mid-level" to make ends meet: Reasoning through the levels of complexity.. Cognition \& Instruction: 1-47.

Lin, M.C., Tutwiler, M.S., \& Chang, C.Y. (2011). Exploring the relationship between virtual learning environment preference, use, and learning outcomes in 10th grade earth science students. Learning, Media and Technology 36(4), 399-417.

Lin, M.C., Tutwiler, M.S., \& Chang, C.Y. (2012). Gender bias in virtual learning environments: an exploratory study. British Journal of Educational Technology 43(2), 59-63.

Metcalf, S., Kamarainen, A., Tutwiler, M.S., Grotzer, T., \& Dede, C. (2011). Ecosystem Science Learning via Multi User Virtual Environments. International Journal of Gaming and Computer-Mediated Simulations. 3(1) 86-90. 
Okuda, Y., Bryson, E.O., DeMaria Jr., S., Jacobson, L., Quinones, J., Shen, B., Levine, A.I. (2009). The Utility of Simulation in Medical Education: What Is the Evidence? Mount Sinai Journal of Medicine, 76, 330-343.

Paulson, A., Perkins, K., \& Adams, W. (2009). How does the type of guidance student use of an interactive simulation? Available: http://phet.colorado.edu/publications/Paulson_etal_2009/Paulson_etal_2009.pdf.

Perkins, D. \& Grotzer, T.A. (2005). Dimensions of causal understanding: The role of complex causal models in students’ understanding of science. Studies in Science Education. 41,117165.

Perkins, D. N., \& Salomon, G. (1988). Teaching for transfer. Educational Leadership, 46, 22-32. Raia, F., (2008). Causality in complex dynamic systems: A challenge in earth systems science education. Journal of Geoscience Education, 56(1) 81-94.

Rubin, D.B. (2005). Causal inferences using potential outcomes. Journal of the American Statistical Association. 100(469): 322-331.

Rutten, N., van Joolingen, W.R., van der Veen, J.T. (2012). The learning effects of computer simulations in science education. Computers \& Education 58(1), 136-153.

Shin, N., Jonassen, D.H., McGee, S. (2003). Predictors of Well-Structured and Ill-Structured Problem Solving in an Astronomy Simulation. Journal of Research in Science Teaching (40)1, 6-33.

Squire, K. (2003). Videogames in education. International Journal of Intelligent Simulations and Gaming. 2(1) 49-62.

Tenner, E. (1996). Why things bite back. New York: Vintage Books. 
United States Census Bureau Website (2011). Factfinder. Retrieved 4 December, 2011 from http://factfinder.census.gov/servlet/SAFFFacts?_event=Search\&geo_id=\&_geoContext=

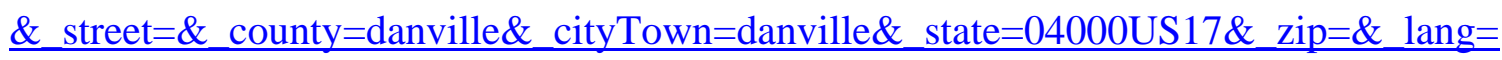
en\&_sse $=$ on\&pctxt $=$ fph\&pgsl $=010 \&$ show $2003 \_$tab $=$\&redirect $=Y$

Walker, B. \& Salt, D. (2006). Resilience thinking: Sustaining ecosystems and people in a changing world. Washington: Island Press.

White, P.A. (1997). Naive ecology: Causal judgments about a simple ecosystem. British Journal of Psychology. 88, 219-233.Wieman, C.E, Adams, W.K., Perkins, K. K. (2008). PhET: Simulations that enhance learning, Science, 322/682-683, October 2008.

Wilensky, U., \& Resnick, M. (1999). Thinking in levels: A dynamic systems approach to making sense of the world. Journal of Science Education and Technology, 8(1), 3-19.Zacharia, Z.C. (2007). Comparing and combining real and virtual experimentation: an effort to enhance students' conceptual understanding of electric circuits. Journal of Computer Assisted Learning. 23(2), 120-132. 


\section{Tables and Figures}

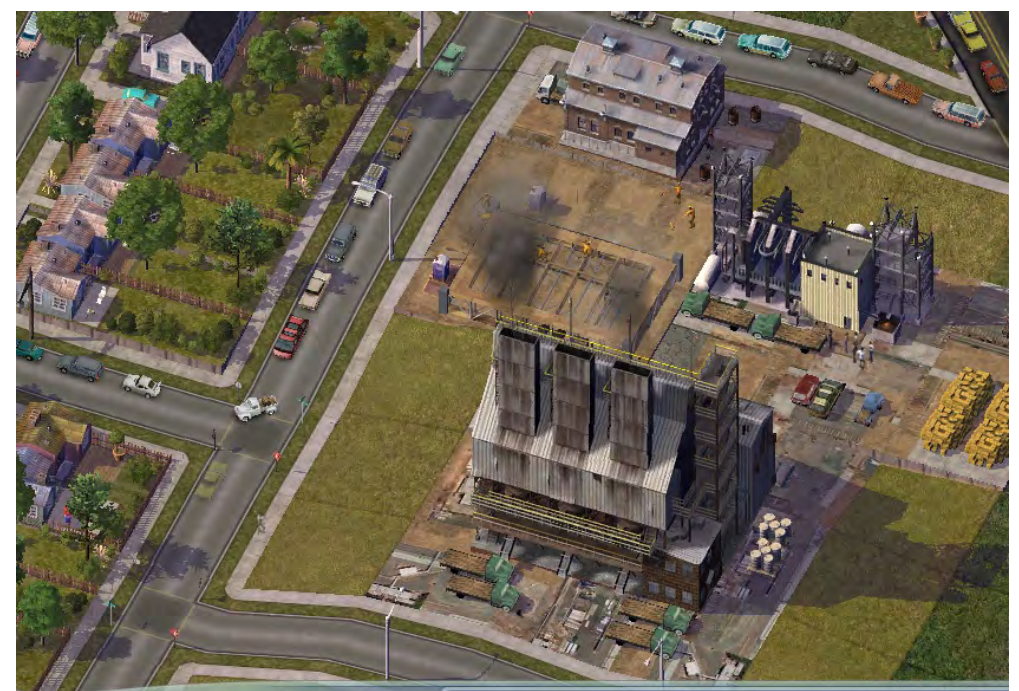

Figure 1. Industrial zone (right) near a residential zone (left) in SimCity 


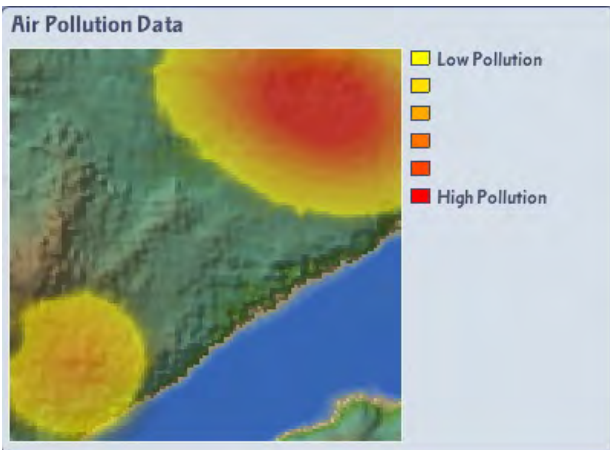

Figure 2. SimCity Air Pollution Data 


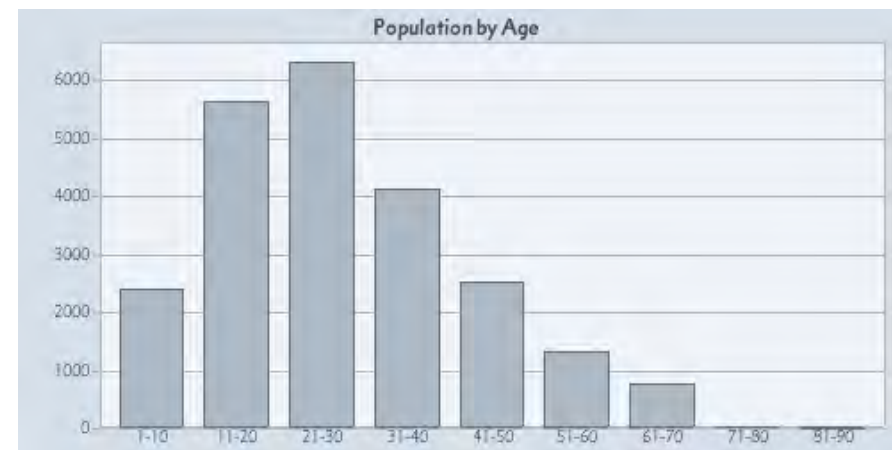

Figure 3. Graph of SimCity population, by age 
Mayor Rating

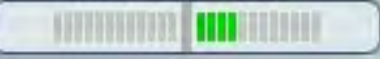

Figure 4. SimCity Mayoral Rating 


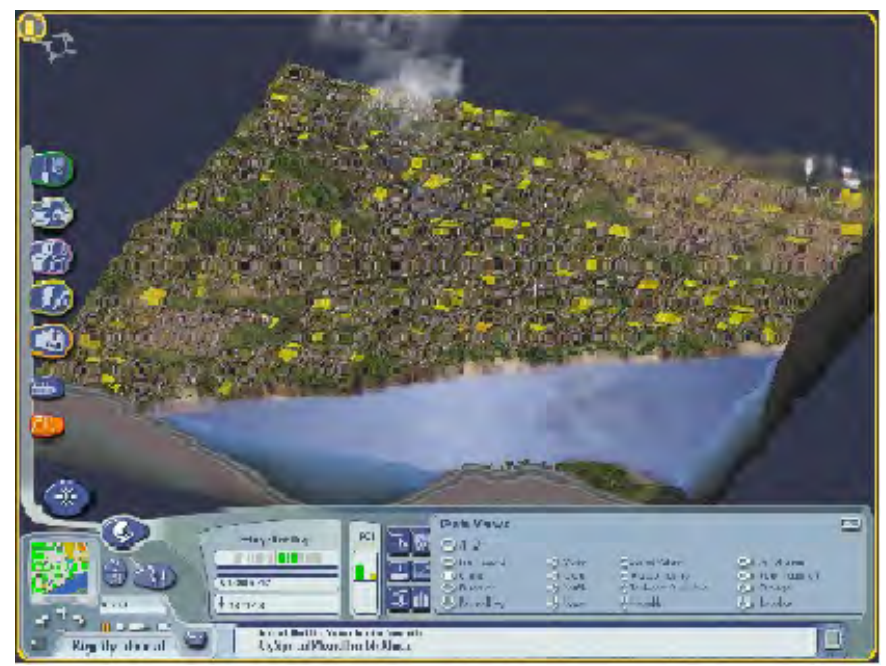

Figure 5. SimCity Crime Map 


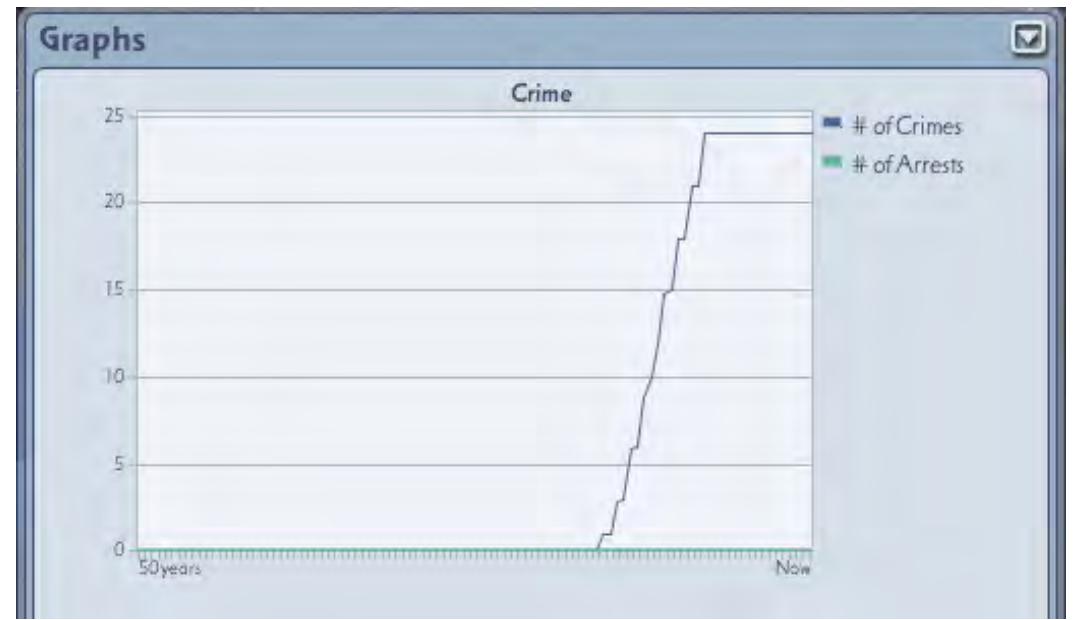

Figure 6. SimCity Crime Graph 


\begin{tabular}{|c|c|c|c|c|c|c|}
\hline \multicolumn{1}{c}{$<$ July 2011} & \\
\hline Sun & Mon & Tue & Wed & Thu & Fri & Sat \\
\hline & & & & & 1 & 2 \\
\hline 3 & 4 & 5 & 6 & 7 & 8 & 9 \\
\hline 10 & 11 & 12 & 13 & 14 & 15 & 16 \\
\hline 17 & 18 & 19 & 20 & 21 & 22 & 23 \\
\hline 24 & 25 & 26 & 27 & $28 *$ & 29 & 30 \\
\hline 31 & & & & & & \\
\hline
\end{tabular}

Figure 7. EcoMUVE Calendar Tool 


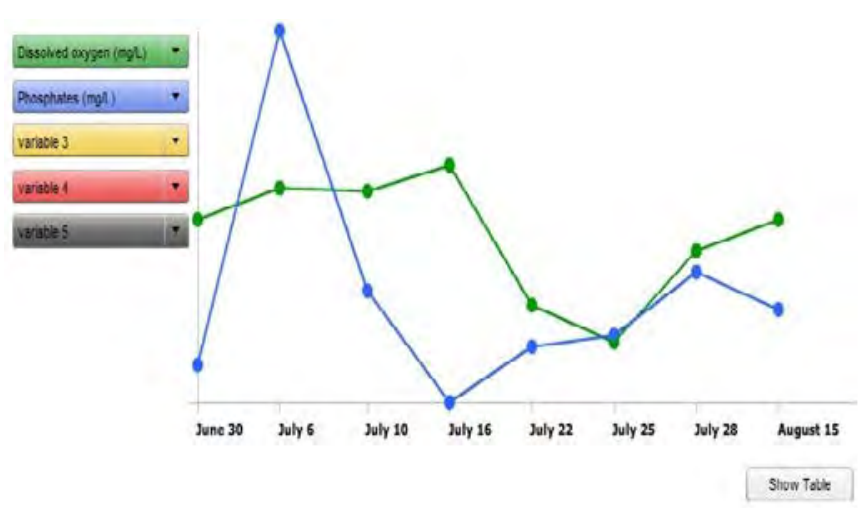

Figure 8. EcoMUVE Data Graph

' Available at: http://mw.concord.org/modeler/index.html [Accessed: 12.20.2011]

ii Available at: http://phet.colorado.edu/en/simulations/category/new [Accessed: 12-20-2011]

iii http://ccl.northwestern.edu/netlogo/docs/faq.html\#diff [Accessed: 12-20-2011]

iv StarLogo Termite Project http://education.mit.edu/starlogo/ [Accessed: 12-20-2011]

${ }^{\mathrm{v}}$ SimCity ${ }^{\mathrm{TM}} 4$ Deluxe can be purchased online (cost, \$20USD at the time of writing) through the Steam content delivery system, or through other commercial gaming vendors. 